\title{
Optimisation of microalgal cultivation via nutrient-enhanced strategies: the biorefinery paradigm
}

\author{
Gonzalo M. Figueroa-Torres ${ }^{1}$, Jon K. Pittman ${ }^{2}$ and Constantinos Theodoropoulos ${ }^{1 *}$ (i)
}

\begin{abstract}
Background: The production of microalgal biofuels, despite their sustainable and renowned potential, is not yet cost-effective compared to current conventional fuel technologies. However, the biorefinery concept increases the prospects of microalgal biomass as an economically viable feedstock suitable for the co-production of multiple biofuels along with value-added chemicals. To integrate biofuels production within the framework of a microalgae biorefinery, it is not only necessary to exploit multi-product platforms, but also to identify optimal microalgal cultivation strategies maximising the microalgal metabolites from which biofuels are obtained: starch and lipids. Whilst nutrient limitation is widely known for increasing starch and lipid formation, this cultivation strategy can greatly reduce microalgal growth. This work presents an optimisation framework combining predictive modelling and experimental methodologies to effectively simulate and predict microalgal growth dynamics and identify optimal cultivation strategies.

Results: Microalgal cultivation strategies for maximised starch and lipid formation were successfully established by developing a multi-parametric kinetic model suitable for the prediction of mixotrophic microalgal growth dynamics co-limited by nitrogen and phosphorus. The model's high predictive capacity was experimentally validated against various datasets obtained from laboratory-scale cultures of Chlamydomonas reinhardtii CCAP 11/32C subject to different initial nutrient regimes. The identified model-based optimal cultivation strategies were further validated experimentally and yielded significant increases in starch $(+270 \%)$ and lipid $(+74 \%)$ production against a non-optimised strategy.

Conclusions: The optimised microalgal cultivation scenarios for maximised starch and lipids, as identified by the kinetic model presented here, highlight the benefits of exploiting modelling frameworks as optimisation tools that facilitate the development and commercialisation of microalgae-to-fuel technologies.
\end{abstract}

Keywords: Modelling, Biofuels, Starch, Lipids, Biorefinery, Microalgae, Chlamydomonas, Optimisation, Nutrient limitation, Mixotrophy

\footnotetext{
*Correspondence: k.theodoropoulos@manchester.ac.uk

1 Department of Chemical Engineering and Analytical Science,

Biochemical and Bioprocess Engineering Group, The University

of Manchester, Manchester M13 9PL, UK

Full list of author information is available at the end of the article
}

\section{Background}

The commercialisation of biofuels, which are potentially promising and sustainable substitutes for fossil-based fuels, has been severely restricted to current feedstock technologies which largely rely upon the use of traditional food-based or lignocellulosic biomass [1-4]. The on-going search for sustainable and renewable feedstock alternatives has led to the recognition of microalgae as a

(c) The Author(s) 2021. This article is licensed under a Creative Commons Attribution 4.0 International License, which permits use, sharing, adaptation, distribution and reproduction in any medium or format, as long as you give appropriate credit to the original author(s) and the source, provide a link to the Creative Commons licence, and indicate if changes were made. The images or other third party material in this article are included in the article's Creative Commons licence, unless indicated otherwise in a credit line to the material. If material is not included in the article's Creative Commons licence and your intended use is not permitted by statutory regulation or exceeds the permitted use, you will need to obtain permission directly from the copyright holder. To view a copy of this licence, visit http://creativeco mmons.org/licenses/by/4.0/. The Creative Commons Public Domain Dedication waiver (http://creativecommons.org/publicdomain/ zero/1.0/) applies to the data made available in this article, unless otherwise stated in a credit line to the data. 
promising long-term feedstock (known as third-generation) capable of meeting global biofuel demands [1, 3 , $5-7]$. The potential of microalgae is highlighted by the typical fast growth rate of many strains, leading to high biomass production, and the ability to accumulate carbohydrate (mainly in the form of starch) and lipids, precursor molecules for sugar-based and oil-based biofuels [8, 9]. Since their cellular composition also includes other industrially important biomolecules (e.g. proteins, pigments, vitamins, and other bioactive compounds) $[5,10]$, microalgae are now positioned as a viable biomass feedstock for biorefineries [5, 11, 12].

Through the full exploitation of the rich cellular composition of microalgae, microalgal biorefineries offer a profitable and competitive approach for the co-production of biofuels along with other high value-added chemicals [12, 13]. Figure 1 shows some of the conversion routes that could be implemented within a biorefinery framework to obtain biofuels and other commercially important products. The implementation of such a framework can help increase energy efficiency and process profitability by optimally integrating all possible bioprocessing routes along with waste re-valorisation scenarios $[5,11]$.
The prospects of microalgae biorefineries are encouraging [13-15], and available technoeconomic analyses show that integrating biofuels conversion routes with other high-value chemicals and/or energy generation systems (e.g. hydrogen, methane) in an integrated biorefinery concept is more economically attractive [16-18]. Technoeconomic studies, however, should be interpreted cautiously due to the often high number of assumptions and degrees of freedom typically used to obtain economic projections. Indeed, despite the promising advantages of integrating biofuels production within a biorefinery network, microalgal biofuel technologies are not yet sufficiently developed to be competitive on their own $[19,20]$. This represents a major drawback that currently prevents microalgal biofuels from being commercialised.

A prevalent challenge of microalgae technologies for biofuels production purposes is the need to identify cultivation strategies that generate mass-scale microalgal cultures rich in starch and lipids, i.e. the biofuel precursors [21-23]. In this regard, it has been widely demonstrated that the cultivation environment can be artificially manipulated to induce starch and lipid accumulation [24, 25]. Nutrient-stressed cultivation

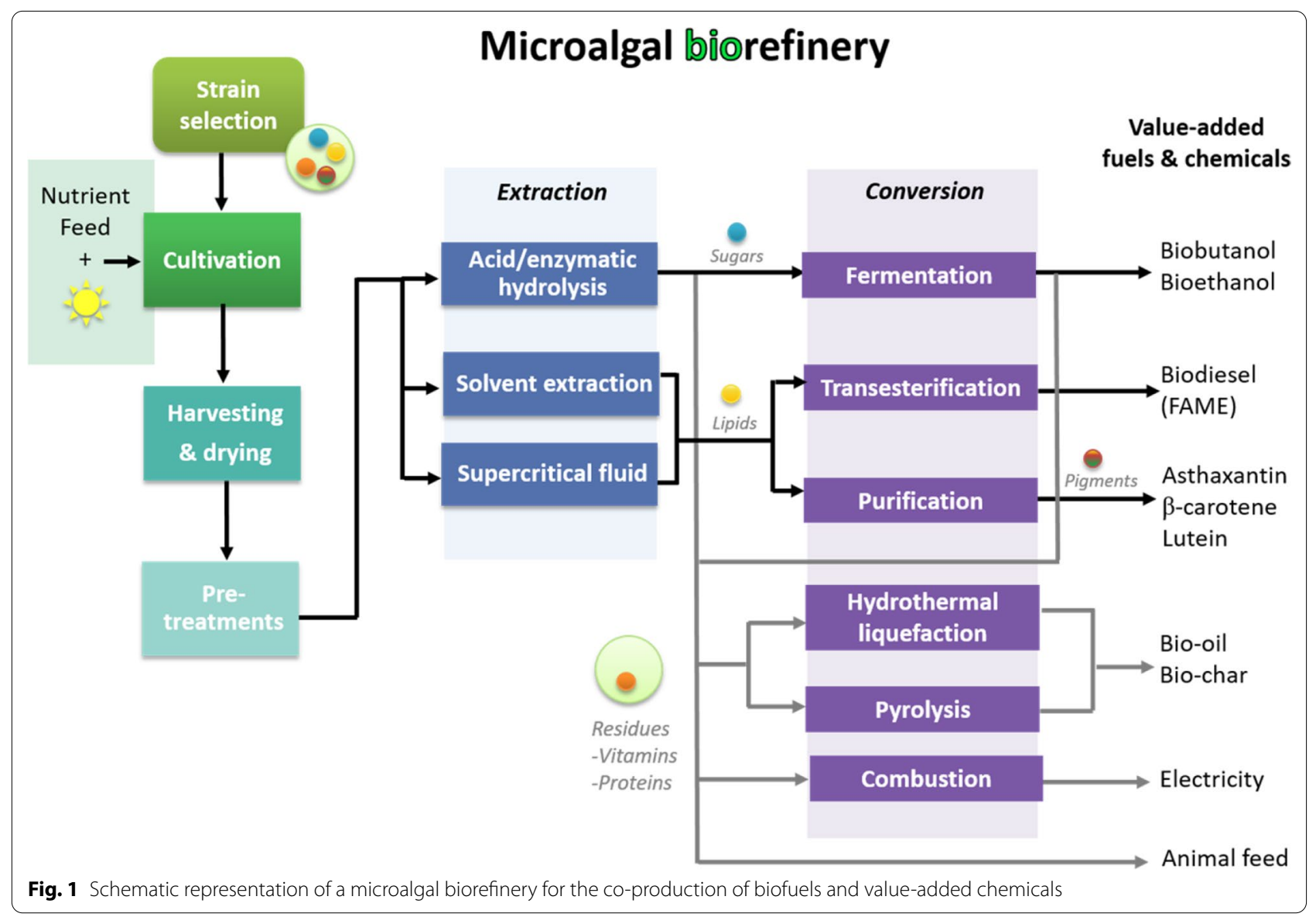


strategies (e.g. nitrogen or phosphorous limitation), in particular, have been established as a simple, costeffective strategy for enhanced starch and lipid formation [24, 26-30]. Nevertheless, nutrient limitation often drastically reduces microalgal growth, which in consequence reduces total starch and lipid productivities [22, 30, 31].

Mixotrophically grown strains (i.e. those that assimilate organic carbon sources in addition to inorganic carbon dioxide) generally attain higher growth rates than typical phototrophic strains (i.e. those that rely solely on inorganic carbon dioxide) [31-33], and thus have the potential of withstanding any adverse effects caused by nutrient limitation. Implementing starch/lipid-enhancing strategies, therefore, relies on the challenging optimisation of microalgae's nutritional requirements (e.g. carbon, nitrogen, phosphorous, etc.) in such a way that the trade-off between microalgal growth and starch and lipid formation is effectively balanced. Predictive models of microalgal growth are therefore essential tools towards identifying optimal cultivation strategies [34].

Here, we present an experimentally validated predictive model for nutrient-limited, mixotrophic microalgal growth that reflects carbon assimilation and carbon partitioning between starch and lipid reserves. The model was exploited to identify nutrient-enhanced microalgal cultivation strategies, which yielded a significant increase in starch $(+270 \%)$ and lipid $(+74 \%)$ production compared to a non-optimised scenario. The optimisation framework that we show here (combining both modelling and experimental methodologies) can thus be applied for the systematic identification of optimal cultivation strategies, increasing the likelihood of establishing competitive biofuel-oriented microalgal biorefineries.

\section{Results}

Evaluating microalgal responses to media composition

In order to build a predictive model capable of portraying nutrient-limited mixotrophic dynamics, we first quantified the effects of initial nutrient availability on microalgal growth and starch and lipid accumulation. To do so, laboratory-scale cultivation experiments were carried out with the model green microalgae Chlamydomonas reinhardtii subject to different initial concentrations (Additional file 1: Table S1) of nitrogen, phosphorus, and acetic acid (as an organic carbon source) until the stationary phase was achieved ( 8 days). The concentrations of nitrogen, phosphorus, and acetic acid in a standard pH-buffered artificial growth medium (TAP medium) commonly used for laboratory cultivation of C. reinhardtii [35], were used as the reference case against which all other nutrient modified cultures were statistically compared ("Methods"). The results of the biomass, starch and lipid responses are summarised in Table 1.

Unmodified (TAP) medium composition yielded a biomass concentration of $0.318 \mathrm{gC} \mathrm{L}^{-1}$, consisting of $5.6 \%$ starch and $14.1 \%$ lipid. When compared to (TAP), all nutrient-limited conditions caused minor reduction in biomass. However, the only statistically significant reduction was observed in the culture grown under simultaneous phosphorus and nitrogen limitation (Low P: Low N) conditions ( $p=0.048$, one-way ANOVA), where biomass concentration dropped $-22 \%$ with respect to (TAP). In line with previous observations [26], nitrogen limitation

Table 1 Biomass, starch, and lipid concentrations in C. reinhardtii at $t=192 \mathrm{~h}$

\begin{tabular}{|c|c|c|c|c|c|c|c|c|c|c|}
\hline \multirow{2}{*}{$\begin{array}{l}\text { Treatment } \\
(\mathrm{TAP})\end{array}$} & \multicolumn{2}{|c|}{ Biomass $\mathrm{gC} \mathrm{L}^{-1}$} & \multicolumn{2}{|c|}{ Starch $\mathrm{gC} \mathrm{L}^{-1}$} & \multicolumn{2}{|c|}{ Starch \% } & \multicolumn{2}{|c|}{ Lipids $\mathrm{gC} \mathrm{L} \mathrm{L}^{-1}$} & \multicolumn{2}{|l|}{ Lipid \% } \\
\hline & 0.318 & - & 0.0179 & - & $5.6 \%$ & & 0.0448 & - & $14.1 \%$ & \\
\hline (Low P: Low N) & 0.247 & $*$ & 0.0414 & $* * *$ & $16.8 \%$ & $* * *$ & 0.0436 & & $17.7 \%$ & \\
\hline$($ Low N) & 0.281 & & 0.0473 & $* * *$ & $16.8 \%$ & $* * *$ & 0.0596 & $*$ & $21.2 \%$ & $* * *$ \\
\hline$($ Med N) & 0.305 & & 0.0309 & $* * *$ & $10.1 \%$ & $*$ & 0.0566 & & $18.6 \%$ & $*$ \\
\hline (Low P) & 0.267 & & 0.0302 & $* * *$ & $11.3 \%$ & $* *$ & 0.0415 & & $15.6 \%$ & \\
\hline (Med P) & 0.294 & & 0.0208 & & $7.1 \%$ & & 0.0419 & & $14.3 \%$ & \\
\hline$($ Low A) & 0.259 & & 0.0128 & & $4.9 \%$ & & 0.0383 & & $14.8 \%$ & \\
\hline$($ High A) & 0.390 & * & 0.0220 & & $5.6 \%$ & & 0.0666 & $* * *$ & $17.1 \%$ & \\
\hline$($ High $A+)$ & 0.414 & $* *$ & 0.0380 & $* * *$ & $9.2 \%$ & & 0.0758 & $* * *$ & $18.3 \%$ & \\
\hline (High A: Low N-) & 0.234 & $*$ & 0.0536 & $* * *$ & $22.9 \%$ & $* * *$ & 0.0479 & & $20.5 \%$ & $* *$ \\
\hline (High A: Low P) & 0.372 & & 0.0304 & $* * *$ & $8.2 \%$ & & 0.0620 & $* *$ & $16.7 \%$ & \\
\hline$($ High $\mathrm{N}++)$ & 0.168 & $* * *$ & 0.0141 & & $8.4 \%$ & & 0.0242 & $* * *$ & $14.4 \%$ & \\
\hline$($ High $\mathrm{P}++)$ & 0.294 & & 0.0155 & & $5.3 \%$ & & 0.0431 & & $14.7 \%$ & \\
\hline$($ High $\mathrm{A}++)$ & 0.294 & & 0.0178 & & $6.1 \%$ & & 0.0421 & & $14.3 \%$ & \\
\hline
\end{tabular}

Asterisks $\left({ }^{*}\right)$ denote significant differences $\left(p<0.05^{*}, 0.01^{* *}, 0.001^{* * *}\right)$ with respect to (TAP), as per one-way ANOVA. Data are the mean of two independent biological replicates 
(Low N) significantly increased both starch and lipid contents up to $16.8 \%$ and $21.2 \%$, respectively (Table 1 ). In contrast, phosphorus limitation (Low P), significantly induced starch accumulation up to $11.3 \%(p=0.006)$ but lipid accumulation was not significantly different under any of the phosphorus-limited scenarios. This included the (Low P: Low N) conditions, where only starch concentration increased significantly $(p<0.001)$ with respect to (TAP). Accumulation of starch rather than lipid molecules during phosphorus limitation can be explained by starch synthesis being the preferred product of carbon assimilation in C. reinhardtii [36], or by the phosphateassociated inhibition of ADP-glucose pyrophosphorylase which regulates starch synthetic pathways $[37,38]$.

Increasing acetic acid concentration significantly increased biomass concentrations up to 23\% in (High A) $(p=0.043)$ and $30 \%$ in (High $\mathrm{A}+)(p=0.009)$ conditions (Table 1). Acetic acid-associated induced growth in C. reinhardtii has been previously described as a consequence of enhanced mixotrophic growing conditions [31, 32]. High acetic acid concentration subject to low phosphorus (High A: Low P) similarly supported higher biomass with respect to (TAP), whereas biomass decreased significantly $(p=0.026)$ in combination with low nitrogen (High A: Low $\mathrm{N}$ ), which indicates the more important role that nitrogen plays in sustaining microalgal growth. With respect to (TAP), the high acetic acid cultures yielded an increase in starch and lipid concentrations, and correspondingly, an increase in contents of up to $9.2 \%$ starch and $18.3 \%$ lipids, as observed in the (High $\mathrm{A}+$ ) treatment. The increase in starch and lipid contents, however, was not statistically significant and thus mainly associated to the higher biomass supported by the internal acetate boost. An exception was the (High A: Low $\mathrm{N}-$ ) culture, which accumulated significantly more starch $(22.9 \%, p<0.001)$ and lipids $(20.5 \%, p=0.002)$ than (TAP) due to the combined effect of the acetate boost with nitrogen stress. This highlights the greater effect of nitrogen over phosphorus limitation in starch and lipid accumulation. Increased lipid concentrations during acetic acid-enhanced cultivation were similarly reported by Bekirogullari et al. [31, 39], while considerably higher accumulation of lipid has been observed in the starchless (sta6) mutant strain when subject to an acetate boost and nitrogen limitation [40, 41].

Extreme high nutrient concentrations [i.e. (High $\mathrm{N}++$ ), (High $\mathrm{P}++$ ), and (High $\mathrm{A}++$ )] inhibited biomass growth in all cases, but significantly so in the (High $\mathrm{N}++)$ treatment $(p<0.001)$ which caused a biomass drop of $-47 \%$. With regard to starch and lipids, these treatments yielded only small increases of up to $8.4 \%$ starch [in (High $\mathrm{N}++$ )] and $14.7 \%$ lipids [in (High $\mathrm{P}++$ )], and were deemed not significant as per the statistical analysis
(Table 1). Therefore, these strategies are inappropriate for large-scale microalgal cultivation. Exploring the full effect of nutrient concentrations on microalgal dynamics is of vital importance to select optimal nutritional composition, but this evaluation requires costly and time-consuming experimental analyses. Therefore, we employed the data collected here to construct, and subsequently validate, a predictive kinetic model for microalgal growth.

\section{Building a predictive model for microalgal growth}

We previously developed a kinetic model for mixotrophic microalgal growth, alongside starch and lipid formation, as a function of initial nitrogen and organic carbon (acetic acid) concentrations [42]. Here, we present a model with markedly improved predictive capabilities by: (i) taking into account the effects of phosphorus concentration on the algal cultivation dynamics, (ii) incorporating the average light intensity received by the microalgal culture, and (iii) improving the starch and lipid formation rate equations. The model state variables are: total biomass $X\left(\mathrm{gC} \mathrm{L}^{-1}\right)$, starch $S\left(\mathrm{gC} \mathrm{L}^{-1}\right)$, lipids $L\left(\mathrm{gC} \mathrm{L}^{-1}\right)$, active biomass $x^{*}\left(\mathrm{gC} \mathrm{L}^{-1}\right)$, nitrogen $N\left(\mathrm{gN} \mathrm{L}^{-1}\right)$, nitrogen quota $q_{N}\left(\mathrm{gN} \mathrm{gC}_{\mathrm{x}}^{-1}\right)$, phosphorus $P\left(\mathrm{gPO}_{4} \mathrm{~L}^{-1}\right)$, phosphorus quota $q_{P}\left(\mathrm{gPO} 4 \mathrm{gC}^{-1}\right)$, and acetic acid $A\left(\mathrm{gC}_{\mathrm{A}}\right.$ $\mathrm{L}^{-1}$ ). Total biomass is assumed to be the sum of active biomass, starch, and lipids (Fig. 2). The model governing equations are explained below.

\section{Specific growth rate}

The specific growth rate, $\mu\left(\mathrm{h}^{-1}\right)$, which describes how cells grow over a period of times is expressed by a quadruple-factor function incorporating the effects of nitrogen, phosphorus, acetic acid, and the light received by the culture:

$$
\mu=\bar{\mu}_{M, \max }(A, \bar{I}) \cdot \min \left[\mu_{N}\left(q_{N}\right), \mu_{P}\left(q_{P}\right)\right] .
$$

The nitrogen-limited, $\mu_{N}$, and phosphorus-limited, $\mu_{P}$, growth rates are subject to a minimum law and are each expressed as Droop functions [43] of the nitrogen quota, $q_{N}$, and the phosphorus quota, $q_{P}$, respectively:

$$
\mu_{N}\left(q_{N}\right)=1-\frac{q_{N, 0}}{q_{N}} ; \mu_{P}\left(q_{P}\right)=1-\frac{q_{P, 0}}{q_{P}} .
$$

Here, $q_{N, 0}\left(\mathrm{gN} \mathrm{gC}^{-1}\right)$ and $q_{P, 0}\left(\mathrm{gPO}_{4} \mathrm{~g} \mathrm{C}^{-1}\right)$ are the minimum nitrogen and phosphorus quotas required to sustain growth, respectively. The maximum mixotrophic specific growth rate, $\bar{\mu}_{M, \max }(A, \bar{I})$, is regulated by the acetate-driven heterotrophic growth rate, $\mu_{H}$, and the light-driven phototrophic growth rate, $\mu_{I}$, both described by an Andrews function [44] to portray substrate-inhibition and photoinhibition, respectively: 


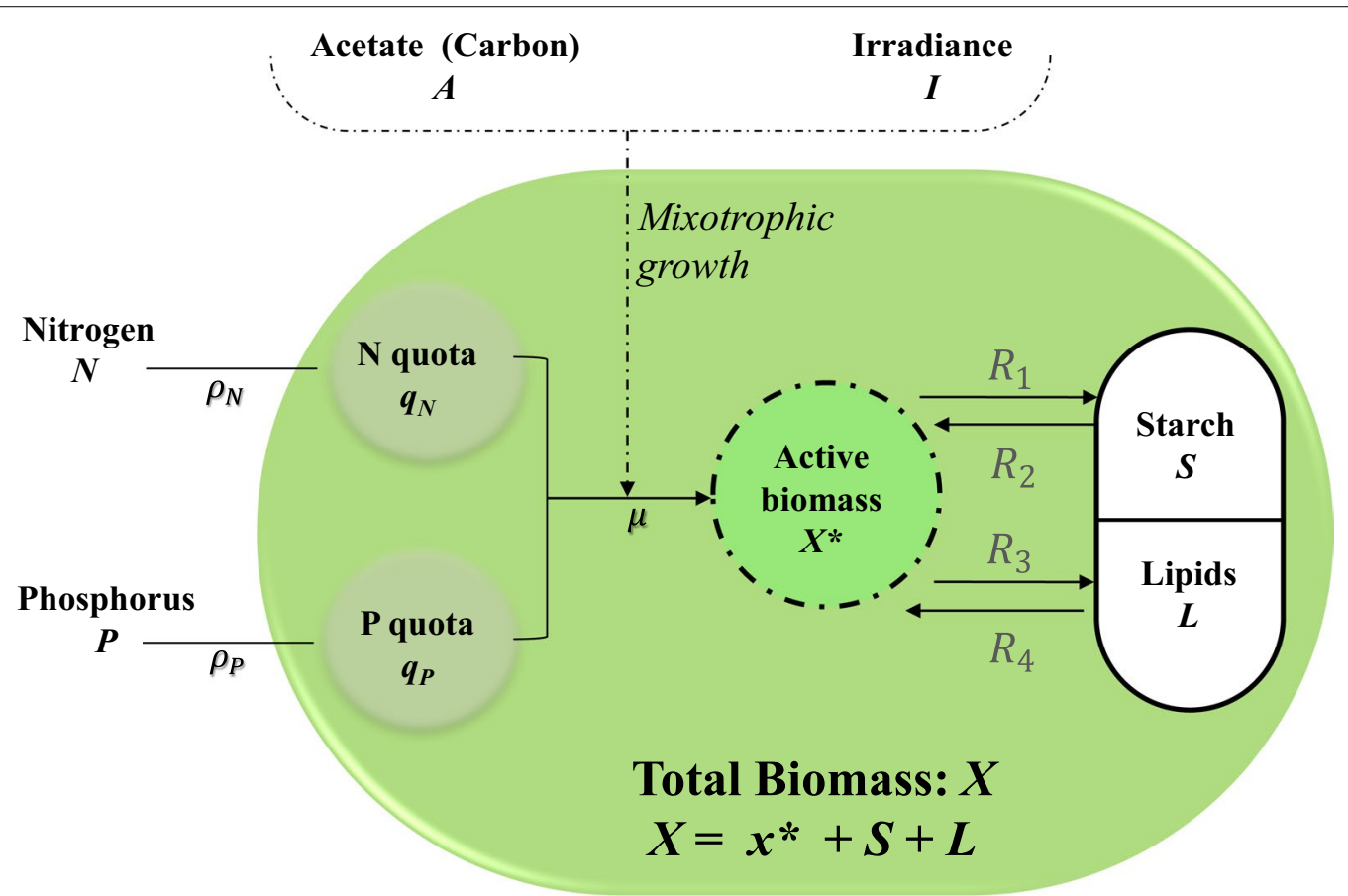

Fig. 2 Schematic representation of the cellular compartments and flows used in the kinetic model. $\mu$, specific growth rate; $\boldsymbol{\rho}_{\boldsymbol{N}}$, nitrogen uptake rate; $\boldsymbol{\rho}_{\boldsymbol{P}}$, nitrogen uptake rate; $\boldsymbol{R}_{\boldsymbol{l}}$ starch synthetic rate; $\boldsymbol{R}_{3}$, lipid synthetic rate; $\boldsymbol{R}_{2}$, starch degradation rate; $\boldsymbol{R}_{4}$, lipid degradation rate

$$
\begin{aligned}
& \bar{\mu}_{M, \max }(A, \bar{I})=\mu_{\max } \cdot\left[w_{H} \cdot \mu_{H}(A)+w_{I} \cdot \mu_{I}(\bar{I})\right], \\
& \mu_{H}(A)=\frac{A}{A+K_{S, A}+A^{2} / K_{i, A}} ; \mu_{I}(\bar{I})=\frac{\bar{I}}{\bar{I}+K_{S, I}+\bar{I}^{2} / K_{i, I}} .
\end{aligned}
$$

Here, $\mu_{\max }\left(\mathrm{h}^{-1}\right)$ is the maximum mixotrophic specific growth rate, $K_{S, A}$ and $K_{i, A}\left(\mathrm{gC} \mathrm{L}^{-1}\right)$ are the acetateassociated half-saturation and inhibition constants, respectively, and $K_{S, I}$ and $K_{i, L}\left(\mu_{\mathrm{mol}} \mathrm{m}^{-2} \mathrm{~s}^{-1}\right)$ are the light-associated half-saturation and inhibition constants, respectively; $w_{H}$ and $w_{I}$ are weighing functions controlling the magnitude of the heterotrophic and phototrophic growth rates, respectively.

Microalgal productivity is dependent on the total amount of photosynthetically active radiation (in the range of 400-700 $\mathrm{nm}$ ) received by microalgal cells [45]. However, even though light might be supplied at a constant intensity, the amount of light received is affected by the cell absorption efficiency as well as by scattering, reflection, and refraction processes [46]. In addition, different wavelengths affect growth rates among microalgae species $[47,48]$. Whilst an accurate representation of the light received by microalgal cultures should account for the above phenomena, a more common yet simple modelling approach relies on estimating the light, $I$ ( $\mu_{\mathrm{mol}}$ $\left.\mathrm{m}^{-2} \mathrm{~s}^{-1}\right)$, at a given culture depth, $z(\mathrm{~m})$, by means of the
Beer-Lambert law, which assumes that light decreases exponentially with increasing biomass growth. Since cells can receive more light at the culture surface than at the bottom, here we use a slightly more accurate representation of the light throughout the vessel by computing an average light intensity, $\bar{I}$, between the surface $(z=0)$, and its depth $(z=L)$, so that [49]:

$$
\bar{I}=\frac{I_{o}}{L} \int_{0}^{L} e^{-\sigma \cdot X \cdot z} \cdot \mathrm{d} z=\frac{I_{0}}{\lambda} \cdot\left(1-e^{-\lambda}\right),
$$

where $\sigma\left(\mathrm{L} \mathrm{gC}^{-1} \mathrm{~m}^{-1}\right)$ is the light attenuation coefficient, and $\lambda=\sigma \cdot X \cdot L$ is the optical depth. It is worth noting that the optical depth can be further improved by considering that light attenuation depends not only on biomass growth, but also on the concentration of chlorophyll and other pigments [50]. The day:light cycle is additionally known to have an effect on biomass growth and in starch and lipid formation. In Chlamydomonas, for example, accumulation of starch and lipids (TAG) was observed to be dependent on whether cells are grown in the light or in the dark [36]. More interestingly, starch accumulation has been reported to be controlled by a circadian clock (as opposed to simple lights-on lights-off periods) which is discontinued following nitrogen starvation [51]. The model presented here aims to portray the macroscopic dynamics of microalgae as a function of nutrient composition and therefore does not consider the photoperiod, 
however the simulation of the specific light-dark cycle can help in the understanding of more complex metabolic pathways occurring in microalgae between day and night.

\section{Nitrogen and phosphorus uptake rates}

Microalgae models commonly employ simple saturationtype kinetics to simulate nutrient consumption $[43,52$, 53]. In this model, however, the nitrogen uptake rate employs inhibition-type kinetics dependent on nitrogen to account for the growth inhibition observed at a high nitrogen concentration [i.e. (High $\mathrm{N}++$ ), Table 1], but also dependent on acetic acid to account for the reduction of nitrogen consumption observed at a high acetic acid concentration [i.e. (High $\mathrm{A}++$ ), Additional file 1, Table S3]. The nitrogen uptake rate, $\rho_{N}\left(\mathrm{gN} \mathrm{gC}^{-1} \mathrm{~h}^{-1}\right)$, is therefore expressed as follows:

$$
\begin{aligned}
\rho_{N}= & \bar{\rho}_{N, \max }\left(N_{0}, X\right) \cdot \frac{N}{N+k_{s, N}+N^{2} / k_{i, N}} \\
& \cdot \frac{A}{A+k_{s, A: N}+A^{2} / k_{i, A: N}} \cdot f\left(q_{P}\right) .
\end{aligned}
$$

Here, $k_{s, N}$ and $k_{i, N}\left(\mathrm{gN} \mathrm{L}^{-1}\right)$ are nitrogen-associated half-saturation and inhibition constants, respectively, and $k_{s, A: N}$ and $k_{i, A: N}\left(\mathrm{gC} \mathrm{L}^{-1}\right)$ are acetate-associated half-saturation and inhibition constants, respectively.

In Eq. (6), $\bar{\rho}_{N, \max }\left(N_{o}, X\right)$ is the maximum nitrogen uptake rate, which accounts for the luxury uptake of nitrogen of microalgal cells (i.e. a phenomenon where the uptake of nutrient is fast immediately after inoculation). Given that the extent of luxury uptake was thought to be dependent on the nutrient concentration of the "fresh" medium and the cell density [54], the maximum nitrogen uptake rate is regulated by the initial nitrogen medium concentration, $N_{0}$, and the biomass concentration, $X$, as:

$$
\bar{\rho}_{N, \max }\left(N_{0}, X\right)=\rho_{N, \max } \cdot \frac{N_{o}^{n}}{N_{o}^{n}+K_{*}^{n}} \cdot e^{-\phi_{N} \cdot X} .
$$

Here $\rho_{N, \max }\left(\mathrm{gN} \mathrm{gC}^{-1} \mathrm{~h}^{-1}\right)$ is the maximum nitrogen uptake rate, $\phi_{N}$ is an uptake regulation coefficient $\left(\mathrm{L} \mathrm{gC}^{-1}\right), n$ is a shape-controlling parameter, and $K_{*}$ is a saturation constant $\left(\mathrm{gN} \mathrm{L}^{-1}\right)$. In Eq. (7), the effect of the initial nitrogen concentration is described using saturation-type kinetics, and the effect of biomass is expressed by an exponential term indicating that the uptake of nitrogen decreases exponentially with increasing biomass concentration.

The above formulation follows the structure proposed in our previous work. However, since the consumption of nitrogen (Figs. 3b and $4 \mathrm{~b}$ ) decreased in those cultures grown in low phosphorous concentrations, the nitrogen uptake rate was additionally regulated by a Droop function of the phosphorus quota, $f\left(q_{P}\right)$ :

$$
f\left(q_{P}\right)=\left(1-\frac{K_{P}}{q_{P}}\right) .
$$

Here, $K_{P}\left(\mathrm{gN} \mathrm{gC}^{-1}\right)$ denotes the minimum $\mathrm{P}$ quota below which nitrogen uptake stops: (i.e. if $q_{P}<K_{q_{P}}$, $\left.\rho_{N}=0\right)$. The negative effect of phosphorus limitation on the cellular mechanisms controlling nitrogen uptake has been previously reported, and is explained by a shortage of nutrient transport energy supplied by phosphoruscontaining molecules such as ATP [52].

The uptake of phosphorus, unlike nitrogen, was not affected by acetic acid and was thus solely expressed in terms of the residual phosphate concentration, $P$, by means of inhibition-type kinetics:

$$
\rho_{P}=\rho_{P, \max } \cdot \frac{P}{P+k_{s, P}+P^{2} / k_{i, P}} \cdot f\left(q_{N}\right) .
$$

Here, $\rho_{P, \max }\left(\mathrm{gPO}_{4} \mathrm{gC}^{-1} \mathrm{~h}^{-1}\right)$ is the maximum phosphorous uptake rate, and $k_{s, P}$ and $k_{i, P}\left(\mathrm{gPO}_{4} \mathrm{gC}^{-1}\right)$ are the phosphorus-associated half-saturation and inhibition constants, respectively. In Eq. (9), $f\left(q_{N}\right)$, is a regulating function dependent on the $\mathrm{N}$ quota which accounts for the negative effects of nitrogen stress on phosphorus uptake, described as:

$$
f\left(q_{N}\right)=\left[1+\left(\frac{\rho_{P, \max }}{q_{N}}\right)^{2}\right]^{-1} .
$$

This function is an inverse adaptation of the classic term used for microbial product inhibition [55], but applied here to decreasing limiting $\mathrm{N}$ quotas. Equation (10) regulates phosphorus uptake as follows: the uptake of phosphorus decreases as the nitrogen quota decreases (i.e. nitrogen-limited conditions). The regulating function shown in Eq. (10) differs from the Droopbased function in Eq. (8) since the effect of nitrogen stress on phosphorous uptake (which reduced gradually-see Figs. 3d and 4d) was observed to be less pronounced than the effects of P-stress on nitrogen uptake (which stops abruptly). A visual comparison between the effects of the functions $f\left(q_{N}\right)$ and $f\left(q_{P}\right)$ on the nutrient uptake rate is available in Additional file 1, Figure S2.

\section{Formation of starch and lipids}

The dynamics of starch and lipid formation are regulated by their synthetic rates, $R_{1}$ and $R_{3}$, and their degradation rates, $R_{2}$ and $R_{4}$, respectively. The synthetic rates are expressed as: 


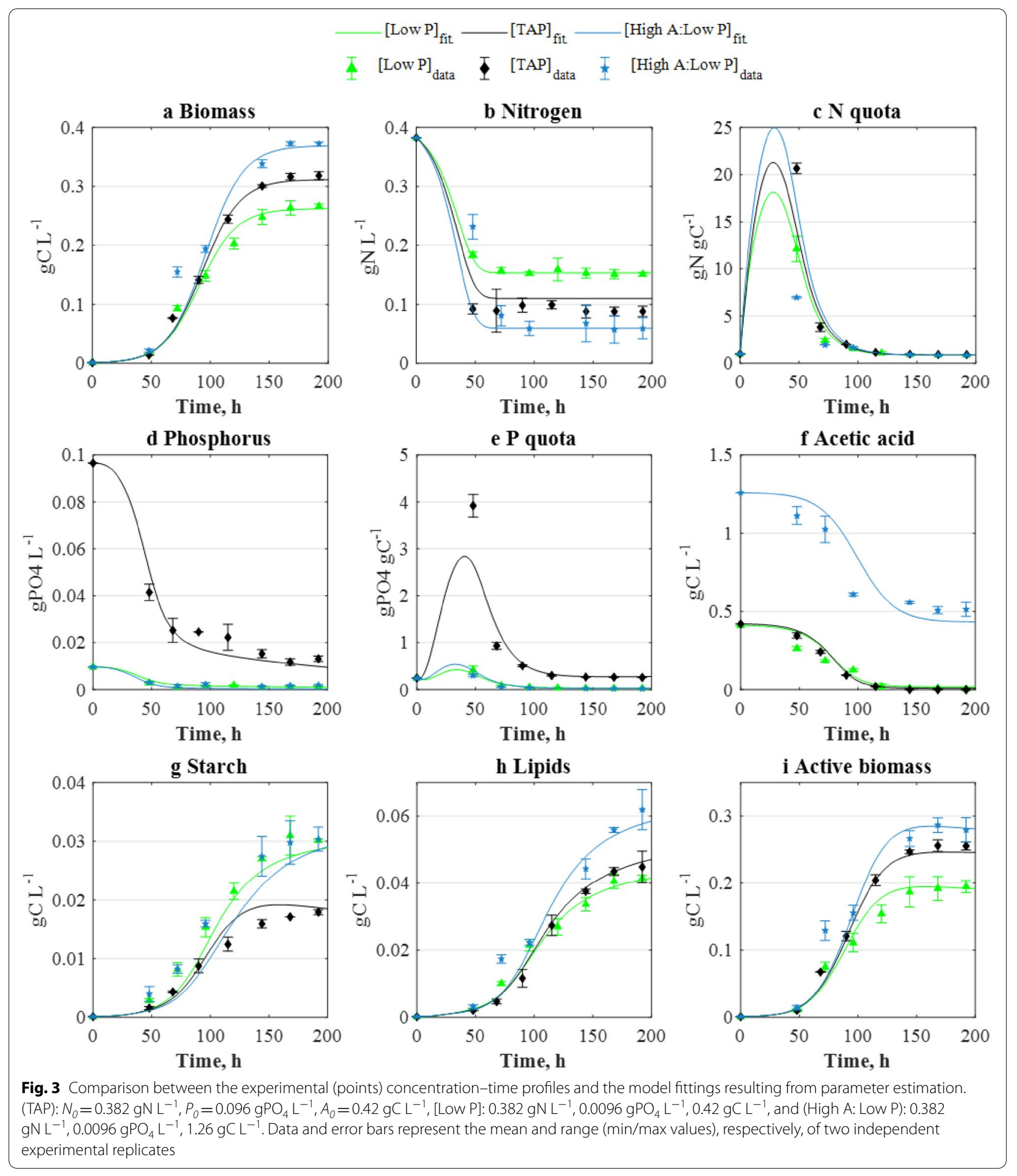

$$
\begin{aligned}
R_{1}= & r_{1} \cdot \frac{N_{i}^{n_{s}}}{N_{i}^{n_{s}}+k_{s, S}^{n_{S}}+\left(N_{i}^{2} / k_{i, S}\right)^{n_{s}}} \cdot \frac{k_{1}}{k_{1}+N / N_{o}} \\
& \cdot\left[1+\frac{1}{\mu} \cdot e^{\phi_{S} * A_{i}}\right] \cdot \mu \cdot x^{*},
\end{aligned}
$$$$
R_{3}=r_{3} \cdot \frac{N_{i}^{n_{L}}}{N_{i}^{n_{L}}+k_{s, L}^{n_{L}}+\left(N_{i}^{2} / k_{i, L}\right)^{n_{L}}} \cdot \frac{k_{2}}{k_{2}+N / N_{0}}
$$$$
\cdot\left[1+\frac{1}{\mu} \cdot e^{\phi_{L} * A_{i}}\right] \cdot \mu \cdot x^{*} \text {. }
$$ 


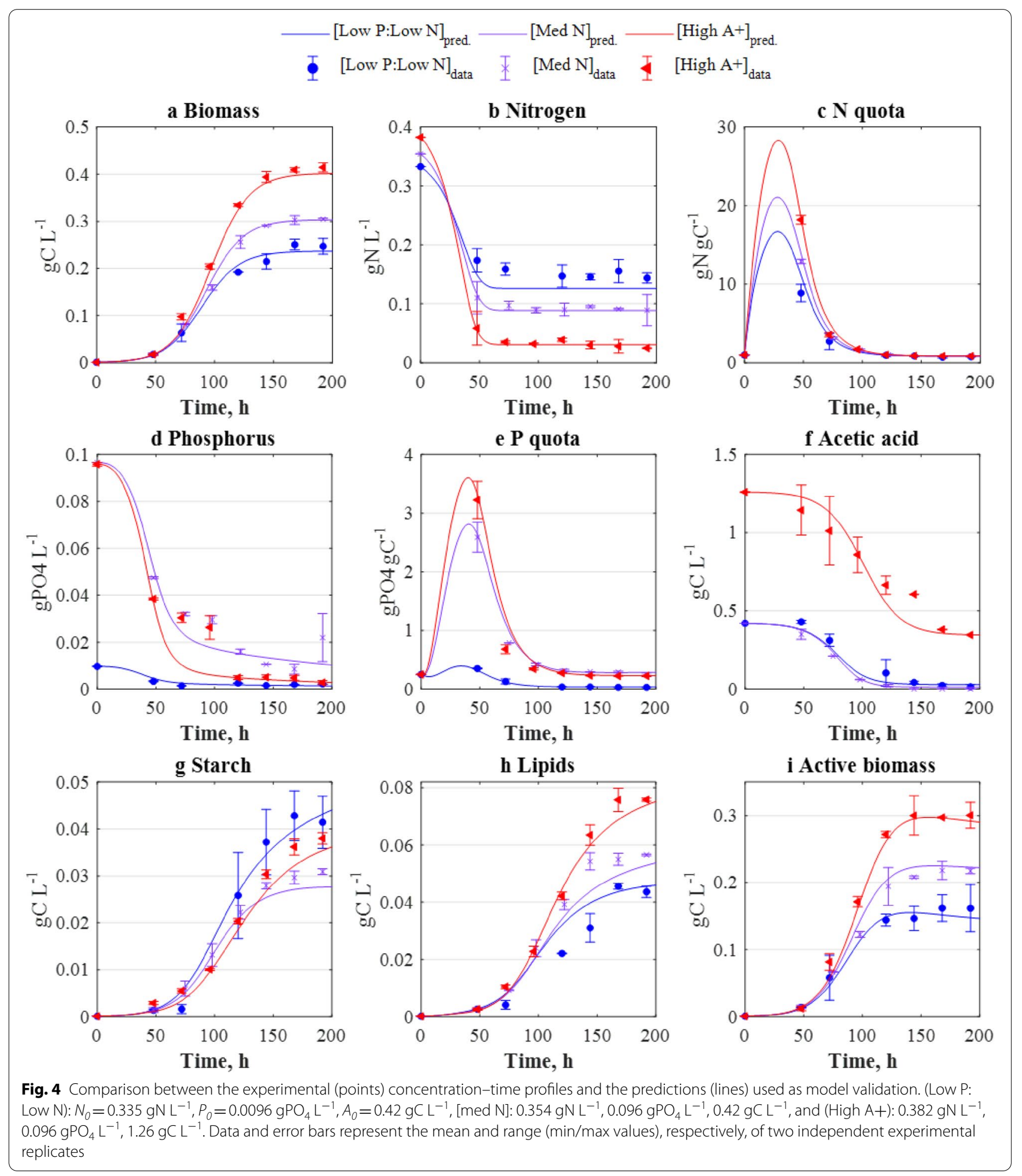

Here, $r_{1}\left(\mathrm{gC} \mathrm{gC}^{-1}\right)$ and $r_{3}\left(\mathrm{gC} \mathrm{gC}^{-1}\right)$ are the rate constants for starch and lipid synthesis, respectively. $k_{s, S}$ and $k_{s, L}\left(\mathrm{gN}_{\mathrm{i}} \mathrm{L}^{-1}\right)$ are saturation constants; $k_{i, S}$ and $k_{i, L}$ $\left(\mathrm{gN}_{\mathrm{i}} \mathrm{L}^{-1}\right)$ are inhibition constants; $\phi_{S}$ and $\phi_{L}\left(\mathrm{~L} \mathrm{gC}^{-1}\right)$ are regulation coefficients; and $k_{1}$ and $k_{2}\left(\mathrm{gN} \mathrm{L}^{-1}\right)$ are regulating constants. The first term in the synthetic rates is an inhibition-type function dependent on the internal nitrogen concentration, $N_{i}=q_{N} \cdot X$, which portrays the 
reduced formation of storage molecules as the internal nitrogen concentration increases (i.e. nitrogen-replete conditions); the shape-controlling parameters, $n_{S}$ and $n_{L}$, are analogous to those employed in the light-limited model of Molina-Grima et al. [56], but denote here the "abruptness" of the transition from nitrogen-limited to nitrogen-replete conditions,

The second term in Eqs. (11) and (12) is a regulating function dependent on the extracellular nitrogen (scaled with respect to nitrogen supplied, i.e. $N / N_{0}$ ) so that storage molecule formation is greater as the residual nitrogen decreases (i.e. nutrient-limited conditions). Finally, the exponential term is dependent on the bioavailable carbon concentration, i.e. $A_{i}=A_{0}-A$, and simulate the increased formation of storage molecule with increasing acetic acid concentration. This increase was considered to be a result of the acetate-induced boost and therefore uncoupled from biomass growth.

The degradation rates of starch and lipids are expressed as follows:

$$
\begin{aligned}
& R_{2}=r_{2} \cdot \frac{X}{q_{N}} \cdot \frac{S / X}{S / X+k_{\mathrm{sat}, S}}, \\
& R_{4}=r_{4} \cdot \frac{X}{q_{N}} \cdot \frac{L / X}{L / X+k_{\mathrm{sat}, L}} .
\end{aligned}
$$

Here, $r_{2}$ and $r_{4}$ are the rate constants for starch and lipid degradation, respectively, and $k_{\mathrm{sat}, \mathrm{S}}$ and $k_{\mathrm{sat}, \mathrm{L}}(\mathrm{gC}$ $\mathrm{gC}^{-1}$ ) are saturation constants. The degradation rates are assumed to be inversely proportional to the nitrogen quota to prevent excessive formation of starch and lipids during extreme nitrogen-limited conditions and maintain the pool of active biomass. The degradation rates additionally incorporate saturating functions which control the extent of starch and lipid degradation and avoid infeasible accumulation scenarios which can arise in absence of saturation (Additional file 1, Figure S3). These functions follow the formulation proposed by Contois [57].

Whilst the synthetic and degradation rates presented above were developed to portray the individual dynamics of starch and lipid during nutrient-limited mixotrophic growth observed in this work, other kinetic expressions have been reported to describe the substrate-to-product interactions leading to starch and lipid formation under other cultivation conditions, including autotrophic growth, limitation by a single nutrient, or light and temperature limitations [34].

\section{Time-dependent equations}

The accumulation rates of the carbon-based cell components (i.e. biomass, starch, lipids, and active biomass) are described by the following set of ordinary differential equations:

$$
\begin{aligned}
& \frac{\mathrm{d} X}{\mathrm{~d} t}=\mu \cdot X, \\
& \frac{\mathrm{d} S}{\mathrm{~d} t}=R_{1}-R_{2}, \\
& \frac{\mathrm{d} L}{\mathrm{~d} t}=R_{3}-R_{4}, \\
& \frac{\mathrm{d} x^{*}}{\mathrm{~d} t}=\frac{\mathrm{d} X}{\mathrm{~d} t}-\left(\frac{\mathrm{d} S}{\mathrm{~d} t}+\frac{\mathrm{d} L}{\mathrm{~d} t}\right) .
\end{aligned}
$$

The extracellular and intracellular (i.e. cell quotas) nutrient dynamics are described by:

$$
\begin{aligned}
& \frac{\mathrm{d} N}{\mathrm{~d} t}=-\rho_{N} \cdot X, \\
& \frac{\mathrm{d} q_{N}}{\mathrm{~d} t}=\rho_{N}-\mu \cdot q_{N}, \\
& \frac{\mathrm{d} P}{\mathrm{~d} t}=-\rho_{P} \cdot X, \\
& \frac{\mathrm{d} q_{P}}{\mathrm{~d} t}=\rho_{P}-\mu \cdot q_{P}, \\
& \frac{\mathrm{d} A}{\mathrm{~d} t}=-\frac{1}{Y_{X / A}} \cdot \frac{\mu_{H}}{\mu_{H}+\mu_{I}} \cdot \frac{\mathrm{d} X}{\mathrm{~d} t} .
\end{aligned}
$$

In Eq. (23), $\mathrm{Y}_{\mathrm{X} / \mathrm{A}}\left(\mathrm{gC} \mathrm{gC}^{-1}\right)$ is the acetate to biomass yield coefficient.

\section{Evaluating the model's predictive performance}

The multi-parametric model proposed above [Eq. (15)Eq. (23)] comprised 37 kinetic parameters (Table 2), which were estimated through a data fitting procedure combining deterministic and stochastic algorithms. The fitting procedure was then followed by a normalised sensitivity analysis to evaluate the response change in a model state variable with respect to a $1 \%$ change in the parameter values (Additional file 1. Figure S6). As a result of this analysis, model parameters were reduced to 35 . The model was then evaluated in terms of its capacity to predict microalgal growth dynamics subject to different nitrogen, phosphorus, and acetic acid concentrations.

As shown in Fig. 3, the concentration-time profiles obtained by the model were observed to be in good agreement with the corresponding experimental 
Table 2 List of parameters in the model for mixotrophic growth co-limited by nitrogen and phosphorus

\begin{tabular}{|c|c|c|c|c|c|}
\hline Type & Symbol & Parameter description & Value & Units & References \\
\hline \multirow[t]{9}{*}{ Associated to growth } & $\mu_{\max }$ & Maximum specific growth rate & 0.106 & $h^{-1}$ & Figueroa-Torres et al. [42] \\
\hline & $q_{N, 0}$ & Minimum nitrogen quota & 0.877 & $\mathrm{gN} \mathrm{gC}^{-1}$ & Figueroa-Torres et al. [42] \\
\hline & $q_{P, 0}$ & Minimum phosphorus quota & 0.016 & $\mathrm{gPO}_{4} \mathrm{gC}^{-1}$ & This work \\
\hline & $K_{s, A}$ & Acetate saturation constant & 1.789 & $\mathrm{gCL}^{-1}$ & Figueroa-Torres et al. [42] \\
\hline & $k_{i, A}$ & Acetate inhibition constant & 0.110 & $g C L^{-1}$ & Figueroa-Torres et al. [42] \\
\hline & $K_{s, l}$ & Light saturation constant & 1.4 & $\mu_{\mathrm{mol}} \mathrm{m}^{-2} \mathrm{~s}^{-1}$ & Mairet et al. [53] \\
\hline & $k_{i, l}$ & Light inhibition constant & 186.5 & $\mu_{\mathrm{mol}} \mathrm{m}^{-2} \mathrm{~s}^{-1}$ & Figueroa-Torres et al. [42] \\
\hline & $Y_{X / A}$ & Acetate yield coefficient & 0.059 & $\mathrm{gC} \mathrm{gC}^{-1}$ & Figueroa-Torres et al. [42] \\
\hline & 6 & Light attenuation coefficient & 1 & $\mathrm{LgC}^{-1} \mathrm{~m}^{-1}$ & Figueroa-Torres et al. [42] \\
\hline \multirow[t]{12}{*}{ Associated to $\mathrm{N}$ and $\mathrm{P}$-uptake } & $\rho_{N, \max }$ & Maximum $\mathrm{N}$ uptake rate & 44.01 & $\mathrm{gNgC}^{-1} \mathrm{~h}^{-1}$ & This work* \\
\hline & $K_{*}$ & Saturation constant, $N_{0}$ & 0.300 & $\mathrm{gN} \mathrm{L}^{-1}$ & This work* \\
\hline & $n$ & Shape-controlling parameter & 14.54 & - & This work* \\
\hline & $\Phi_{N}$ & N Uptake regulation coefficient & 143.9 & $\mathrm{LgC}^{-1}$ & This work* \\
\hline & $K_{s, N}$ & Uptake saturation constant, $N$ & 0.163 & $\mathrm{gN} \mathrm{L}^{-1}$ & Figueroa-Torres et al. [42] \\
\hline & $k_{i, N}$ & Uptake inhibition constant, $N$ & 0.113 & $\mathrm{gN} \mathrm{L}^{-1}$ & Figueroa-Torres et al. [42] \\
\hline & $K_{S, A: N}$ & Uptake saturation constant, $A: N$ & 1.004 & $g C L^{-1}$ & Figueroa-Torres et al. [42] \\
\hline & $k_{i, A: N}$ & Uptake inhibition constant, A:N & 1.098 & $\mathrm{gCL}^{-1}$ & Figueroa-Torres et al. [42] \\
\hline & $K_{p}$ & P quota supporting $N$ uptake & 0.057 & $\mathrm{gPO}_{4} \mathrm{gC}^{-1}$ & This work \\
\hline & $\rho_{P, \max }$ & Maximum $\mathrm{P}$ uptake rate & 21.10 & $\mathrm{gPO}_{4} \mathrm{gC}^{-1} \mathrm{~h}^{-1}$ & This work \\
\hline & $K_{s, p}$ & Uptake saturation constant, $P$ & 2.299 & $\mathrm{gPO}_{4} \mathrm{~L}^{-1}$ & This work \\
\hline & $k_{i, p}$ & Uptake inhibition constant, $P$ & 0.004 & $\mathrm{gPO}_{4} \mathrm{~L}^{-1}$ & This work \\
\hline \multirow[t]{16}{*}{ Associated to starch and lipid formation } & $r_{1}$ & Starch formation rate $\left(R_{1}\right)$ & 0.058 & $\mathrm{gC} \mathrm{gC}^{-1}$ & This work* \\
\hline & $K_{s, S}$ & Saturation constant $\left(R_{1}\right)$ & 0.000 & $\mathrm{gN} \mathrm{L}^{-1}$ & This work* \\
\hline & $k_{i, S}$ & Inhibition constant $\left(R_{l}\right)$ & 0.205 & $\mathrm{gN} \mathrm{L}^{-1}$ & This work* \\
\hline & $n_{S}$ & Shape parameter $\left(R_{p}\right)$ & 4.17 & - & This work* \\
\hline & $k_{1}$ & Regulation constant $\left(R_{p}\right)$ & 0.108 & - & This work* \\
\hline & $\Phi_{S}$ & Regulation coefficient $\left(R_{p}\right)$ & 0.775 & $\mathrm{LgC}^{-1}$ & This work* \\
\hline & $r_{2}$ & Starch degradation rate $\left(R_{2}\right)$ & 0.005 & $g C \mathrm{gC}^{-1}$ & This work* \\
\hline & $k_{\text {sat }, S}$ & Starch saturation constant $\left(R_{2}\right)$ & 0.018 & - & This work \\
\hline & $r_{3}$ & Lipid formation rate $\left(R_{3}\right)$ & 0.191 & $\mathrm{gNgC}^{-1} \mathrm{~h}^{-1}$ & This work* \\
\hline & $K_{s, L}$ & Saturation constant $\left(R_{3}\right)$ & 0.012 & $\mathrm{gN} \mathrm{L}^{-1}$ & This work* \\
\hline & $k_{i, L}$ & Inhibition constant $\left(R_{3}\right)$ & 0.091 & $\mathrm{gN} \mathrm{L}^{-1}$ & This work* \\
\hline & $n_{L}$ & Shape parameter $\left(R_{3}\right)$ & 2.01 & - & This work* \\
\hline & $k_{2}$ & Regulation constant $\left(R_{3}\right)$ & 0.153 & - & This work* \\
\hline & $\Phi_{L}$ & Regulation coefficient $\left(R_{3}\right)$ & 0.000 & $\mathrm{LgC}^{-1}$ & This work* \\
\hline & $r_{4}$ & Lipid degradation rate $\left(R_{4}\right)$ & 0.007 & $\mathrm{gNgC}^{-1} \mathrm{~h}^{-1}$ & This work* \\
\hline & $k_{\text {sat }, L}$ & Lipid saturation constant $\left(R_{4}\right)$ & 0.079 & - & This work \\
\hline
\end{tabular}

* Parameter values were re-identified from those established in Figueroa-Torres et al. [42]

datasets used for parameter estimation. The model outcomes were subsequently validated against different cultivation regimes, similarly yielding a good agreement between model-predicted and experimental data and (Fig. 4). Parity plots showing the level of agreement between experimental and model-derived data can be found in the Additional file 1: Figure S4. The computed mean correlation coefficient $\left(r^{2}\right)$ between the experimental and model-derived (fitting and validation) datasets averaged $r^{2}=0.95$, highlighting the model's high predictive capacity, and indicating that the model adequately portrays growth, nutrient uptake, and starch and lipid formation in C. reinhardtii.

It is worth mentioning here that despite the robustness of the model for a wide range of environmental conditions, established through extensive experimental validation, the relatively large number of kinetic parameters incorporated might lead to identifiability issues, requiring additional work to compute the "true" optimal values of the model parameters. 
The model was then exploited to compute the formation of biomass, starch, and lipids at the 8th day $(t=192 \mathrm{~h})$ of cultivation, subject to various initial nitrogen (0.25-0.75 $\left.\mathrm{gN} \mathrm{L} \mathrm{L}^{-1}\right)$, phosphorus (0-0.14 $\left.\mathrm{gPO}_{4} \mathrm{~L}^{-1}\right)$, and acetic acid $\left(0-3.5 \mathrm{gC} \mathrm{L}^{-1}\right)$ concentrations. The results are presented as three individual ternary diagrams (Fig. 5), each showing predicted biomass, starch, and lipids (model outputs) in response to initial nutrient concentrations (model inputs). The ternary diagrams show the corresponding changes in starch and lipid formation when subject to nitrogen and phosphorus co-limitation, and allow identification of the required nutrient characteristics to maximise starch and lipid formation during acetate-driven mixotrophic growth.

\section{Maximising microalgal starch and lipid formation}

The ternary diagrams were employed to identify the optimal nutritional requirements (i.e. nitrogen, phosphorus, and acetic acid) maximising starch and lipid concentrations, identified as: (i) "starch-enhancing" medium: $\left[N_{o}=0.33 \mathrm{gN} \mathrm{L}^{-1}, P_{0}=0.052 \mathrm{gPO}_{4} \mathrm{~L}^{-1}, A_{o}=0.96 \mathrm{gC}_{\mathrm{A}}\right.$ $\mathrm{L}^{-1}$ ], yielding $0.33 \mathrm{gC} \mathrm{L}^{-1}$ biomass with $21 \%$ starch and $22 \%$ lipids, and (ii) "lipid-enhancing" medium $\left[N_{o}=0.35\right.$ $\left.\mathrm{gN} \mathrm{L}^{-1}, P_{0}=0.044 \mathrm{gPO}_{4} \mathrm{~L}^{-1}, A_{o}=0.96 \mathrm{gC} \mathrm{L}^{-1}\right]$, yielding $0.38 \mathrm{gC} \mathrm{L}^{-1}$ biomass with $15 \%$ starch and $21 \%$ lipids. The predicted outcome of the optimised scenarios was additionally verified by growing two lab-scale cultures of $C$. reinhardtii subject to the above optimal medium compositions. As observed in Fig. 6, both of the modelbased optimal cultivation scenarios agreed well with the corresponding experimental data. Compared to (TAP) medium, starch-enhancing conditions yielded increases of $270 \%$ and $56 \%$ in starch and lipid concentrations, respectively, whereas lipid-enhancing conditions yielded increases of $203 \%$ and $74 \%$ in starch and lipid concentrations, respectively.

\section{Discussion}

Many species of microalgae respond to nutrient limitation by significantly altering central carbon metabolism pathways and intracellular carbon partitioning, leading to compositional changes which generally favour accumulation of storage molecules [24, 33, 58]. As observed in Table 1, nitrogen and phosphorus limitation resulted in greater starch and lipids contents. Although nitrogen and phosphorus limitation are among the most extensively proven cultivation strategies for starch and lipid accumulation, studies have mainly evaluated such strategies under either complete starvation or single-nutrient limitation [24, 27, 59-61]. Few works evaluate the accumulation of storage molecules under different degrees of nutrient co-limitation $[26,28]$ which is characterised

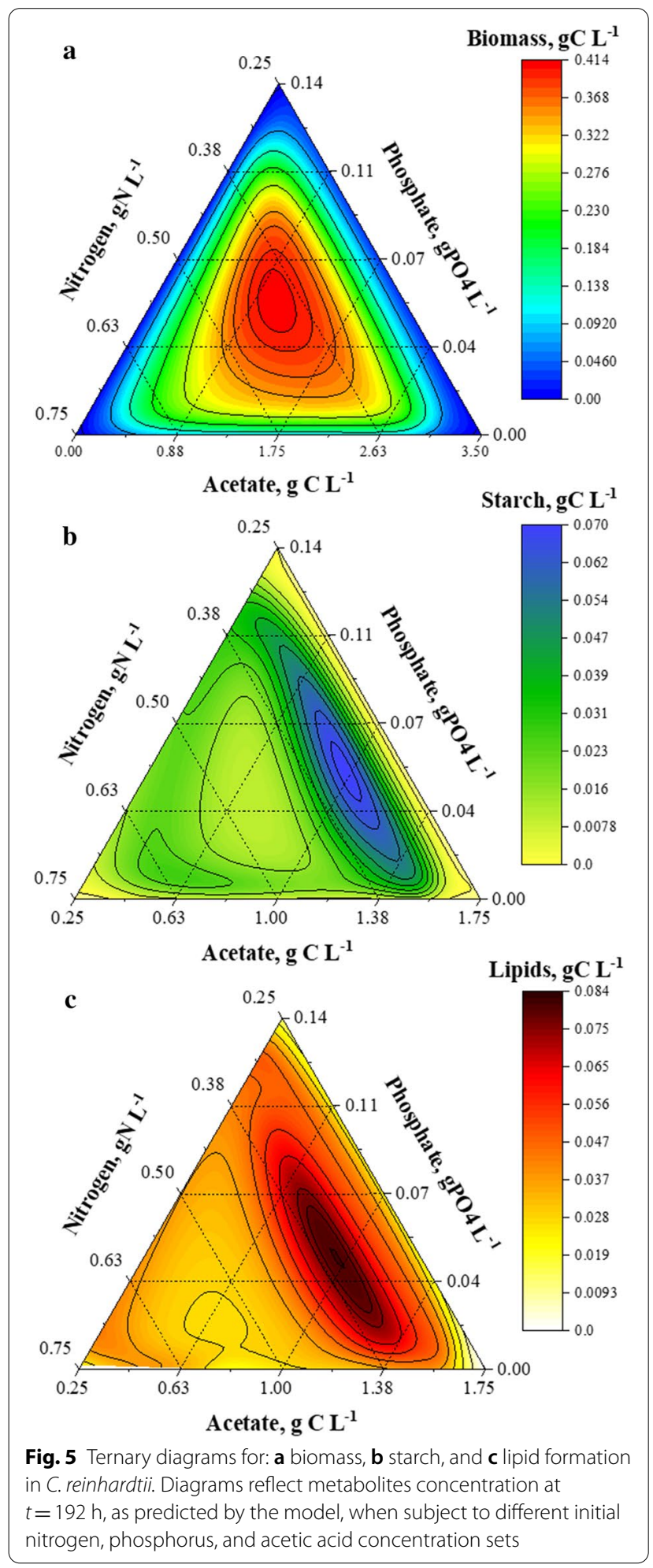

by a trade-off between microalgal growth and starch and lipid accumulation. As evidenced here, however, such a trade-off was overcome by the gradual increase of acetic 

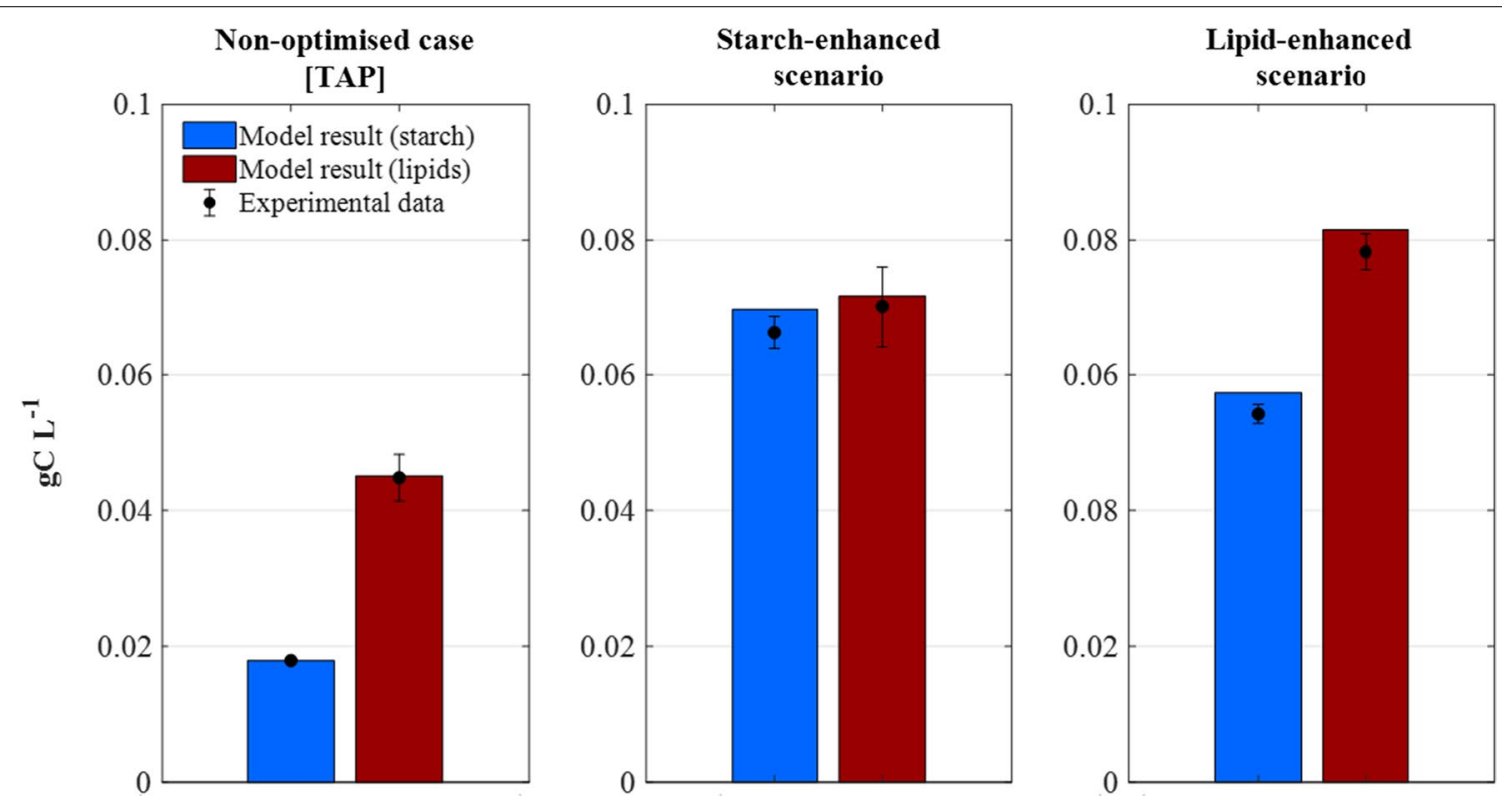

Fig. 6 Comparison of model results and experimental data (dots) from the non-optimised, and model-based optimised scenarios for maximised starch and lipid formation. Non-optimised medium $\left.\left(N_{0}=0.382 \mathrm{gN} \mathrm{L}^{-1}, P_{0}=0.096 \mathrm{gPO}_{4} \mathrm{~L}^{-1}, A_{0}=0.42 \mathrm{gC} \mathrm{L}\right)^{-1}\right)$, starch-enhancing medium $\left(N_{0}=0.33\right.$ $\left.\mathrm{gN} \mathrm{L}^{-1}, P_{0}=0.052 \mathrm{gPO}_{4} \mathrm{~L}^{-1}, A_{0}=0.96 \mathrm{gC} \mathrm{L}^{-1}\right)$, and lipid-enhancing medium $\left(N_{0}=0.35 \mathrm{gN} \mathrm{L}^{-1}, P_{0}=0.044 \mathrm{gPO}_{4} \mathrm{~L}^{-1}, A_{0}=0.96 \mathrm{gC} \mathrm{L}{ }^{-1}\right)$. Data and error bars represent the mean and range ( $\mathrm{min} / \mathrm{max}$ values), respectively, of two independent experimental replicates

acid (i.e. the mixotrophic carbon source) which resulted in higher biomass production and, consequently, higher starch and lipid production.

Nutrient-limited mixotrophic cultivation is thus a suitable cultivation strategy for the purposes of biofuels production, but its implementation is dependent on the identification of an optimal nutrient composition. The multi-parametric kinetic model presented here, developed through a combination of experimental and computational tools, was shown to be a robust tool for the simulation of mixotrophic microalgal growth subject to a wide range of nutrient compositions (Figs. 3 and 4). The developed model was thus further exploited to identify starch-enhancing and lipid-enhancing cultivation strategies and, when compared to a non-optimised scenario, the model-identified strategies yielded significant increases of $+270 \%$ starch and $+74 \%$ lipids.

In line with these optimal scenarios, co-limitation by nitrogen and phosphorus can significantly induce starch and lipid formation, but provided that reduced growth rates are overcome via the supply of sufficient acetic acid, i.e. carbon source. Both nitrogen and phosphorous are essential nutrients that make up important biomolecules such as proteins, pigments, phospholipids, nucleic acids, RNA and DNA, which regulate vital metabolic processes (e.g. the photosynthetic pathway by which carbon is fixated) [24, 62]. Therefore, the enhanced effect of acetic acid supplementation would only be attained if the concentrations of nitrogen and phosphorous allow for growth to take place. As observed in the ternary diagrams shown in Fig. 5, such optimal conditions can be established at the onset of batch cultivation. However, it is worth noting that other operating strategies involving fed-batch or continuous operation will require a balanced supply of nutrients preventing their exhaustion in the cultivation medium.

From an economic perspective the organic carbon requirements may restrict mixotrophic cultivation, but this could be avoided by adequately integrating wastewater effluents rich in organic matter with microalgal growth $[63,64]$. The validated optimal nutrient compositions identified here thus offer a promising and sustainable outlook for the scaling-up of microalgal cultivation systems for biorefinery applications where, on one hand, biofuel precursor molecules are maximised and, on the other, nutrient supply is efficiently and sustainably managed (for instance, by reducing the environmental impacts of nitrogen fertilisers or the overuse of inorganic phosphorus, a non-renewable resource [65]).

\section{Conclusions}

The multi-parametric kinetic model presented here, developed through a combination of experimental and computational tools, was shown to be a robust tool for the simulation of mixotrophic microalgal growth subject to a wide range of nutrient compositions. The developed 
model was further exploited to identify starch-enhancing and lipid-enhancing cultivation strategies relying on optimal nutrient composition. When compared to a non-optimised scenario, the model-identified strategies yielded significant increases of $+270 \%$ starch and $+74 \%$ lipids. Establishing highly productive microalgal cultivation strategies is one of the major challenges preventing microalgal biomass to be implemented as feedstock for biofuels production. However, the model-based optimisation framework presented in this work can be systematically applied to identify and implement tailor-made cultivation strategies yielding mass-scale microalgal cultures rich in starch and lipids and thus contribute to the commercialisation of microalgal biofuels, and together with on-going technological advances, the establishment of microalgal biorefineries.

\section{Methods}

\section{Strain and cultivation}

Experiments were carried out with the wild-type strain Chlamydomonas reinhardtii CCAP 11/32C. The strain was grown mixotrophically in Tris-Acetate-Phosphate (TAP) medium [35]: $2.42 \mathrm{~g}$ of Tris-base, $25 \mathrm{~mL}$ of TAP salts $\left(15 \mathrm{~g} \mathrm{~L}^{-1} \mathrm{NH}_{4} \mathrm{Cl}, 4 \mathrm{~g} \mathrm{~L}^{-1} \mathrm{MgSO}_{4} \cdot 7 \mathrm{H}_{2} \mathrm{O}, 2 \mathrm{~g}\right.$ $\mathrm{L}^{-1} \mathrm{CaCl}_{2} \cdot 2 \mathrm{H}_{2} \mathrm{O}$ ), $0.387 \mathrm{~mL}$ of phosphate buffer $2.7 \mathrm{M}$ (288 g L ${ }^{-1} \mathrm{~K}_{2} \mathrm{HPO}_{4}, 144 \mathrm{~g} \mathrm{~L}^{-1} \mathrm{KH}_{2} \mathrm{PO}_{4}$ ), $1 \mathrm{~mL}$ of trace components [66], and $1 \mathrm{~mL}$ of acetic acid, brought to $1 \mathrm{~L}$ with deionised water. For nutrient-dependent experiments a microalgal inoculum was propagated in $150 \mathrm{~mL}$ of TAP medium until the late stationary phase (5-7 days), reaching a cell dry weight of $0.001 \mathrm{~g} \mathrm{~mL}^{-1}\left(5.47 \times 10^{6}\right.$ cells $\left.\mathrm{mL}^{-1}\right)$. The inoculum was placed in an orbital shaker at $150 \mathrm{rpm}, 25^{\circ} \mathrm{C}$. Illumination (at $125 \mu \mathrm{mol} \mathrm{m}^{-2} \mathrm{~s}^{-1}$ ) was provided from above using $4 \mathrm{ft}$ long $20 \mathrm{~W}$ high-power LED T8 tube lights in a light/dark photoperiod of $16 / 8 \mathrm{~h}$, and the length of light path was $0.15 \mathrm{~m}$.

\section{Nutrient-dependent cultures}

Mixotrophic growth dynamics co-limited by nitrogen and phosphorus were evaluated by growing microalgal cultures under different initial nitrogen $\left(N_{0}\right)$, phosphorus $\left(P_{0}\right)$, and acetic acid $\left(A_{0}\right)$ concentrations with respect to standard (TAP) medium (Table 1). Cultures were grown in duplicate in $500 \mathrm{~mL}$ of sterile medium, inoculated with $1 \mathrm{~mL}$ of active microalgal inoculum, and kept at the environmental conditions described above. Cultures were fully harvested during cultivation (days 2, 3, 4, 6, 7, and 8 ) to analyse biomass and metabolites. Data was statistically analysed by one-way ANOVA in Origin Pro 2017 (b9.4.1.354).

During media preparation, the initial nitrogen concentration was altered by modifying the concentration of ammonium chloride $\left(\mathrm{NH}_{4} \mathrm{Cl}\right)$ in the TAP salts solution. Initial phosphorus concentration was altered by modifying accordingly the volume of phosphate buffer (maintaining a 2:1 ratio for $\mathrm{K}_{2} \mathrm{HPO}_{4}: \mathrm{KH}_{2} \mathrm{PO}_{4}$ ). In phosphorus-limited media, potassium chloride $(\mathrm{KCl})$ was uniformly added to compensate for the loss of potassium ions. Initial acetic acid concentration was altered by modifying the volume of acetic acid. The concentration of all other TAP components remained unchanged, and the initial medium $\mathrm{pH}$ was adjusted to 7 with $\mathrm{HCl} 3 \mathrm{M}$ or $\mathrm{KOH} 3 \mathrm{M}$, as appropriate.

\section{Analytical methods Cell growth}

The dry cell weight (DCW) was quantified by centrifuging microalgal cultures for $3.5 \mathrm{~min}$ at $3000 \mathrm{~g}$ in an Eppendorf centrifuge 5424 . The residual cell pellets were placed in pre-weighed tubes and allowed to dry for $24 \mathrm{~h}$ at $70{ }^{\circ} \mathrm{C}$, after which the DCW was determined gravimetrically. Dried pellets were kept in sealed containers and analysed for their lipid content.

\section{Starch and lipid contents}

For analysis of microalgal starch, 2-mL aliquot samples of microalgal cultures were pelleted by centrifugation at $13,000 \mathrm{~g}$ for $3 \mathrm{~min}$. Chlorophyll was removed by washing pelleted cells in $500 \mu \mathrm{L}$ of $80 \%$ ethanol for $5 \mathrm{~min}$ at $85^{\circ} \mathrm{C}$. Washed cells were re-centrifuged at 13,000 $\mathrm{g}$ for $3 \mathrm{~min}$, and cellular starch was then solubilised as described in Bajhaiya et al. [26]). Total starch was quantified as per a Total Starch enzymatic assay kit (Megazyme International) where released free D-glucose is measured colourimetrically against a D-glucose standard curve. The lipid content of cells (previously pulverised) was determined by solvent extraction (using hexane at $155{ }^{\circ} \mathrm{C}$ ) in a SOXTEC Unit 1043 following a three-stage extraction protocol [31]. Extracted lipids were then quantified gravimetrically.

\section{Metabolites concentrations}

Acetic acid was quantified by high-pressure liquid chromatography (HPLC) in a HPX-87H column $(8 \mu \mathrm{m}$, $300 \times 7.7 \mathrm{~mm}$, Bio-Rad), coupled to a UV detector set at $210 \mathrm{~nm}$. Sulphuric acid $\left(\mathrm{H}_{2} \mathrm{SO}_{4}\right) 5 \mu \mathrm{M}$ was used as the mobile phase at a flow rate of $0.6 \mathrm{~mL} \mathrm{~min}^{-1}$ and a temperature of $50{ }^{\circ} \mathrm{C}$. Total nitrogen was measured in a Total Organic Carbon/Total Nitrogen unit $\left(\mathrm{TOC} \mathrm{V}_{\mathrm{CSH}} /\right.$ TNM-1 Shimadzu) as per manufacturer's instructions. For calibration standards, ammonium chloride $\left(\mathrm{NH}_{4} \mathrm{Cl}\right)$ was used as the nitrogen source. Phosphorus was measured by Inductively Coupled Plasma-Optical Emission Spectroscopy (ICP-OES) in a Varian Vista MPX set at $213 \mathrm{~nm}$. All samples and calibration standards were filtered through $0.45 \mu \mathrm{m}$ nitrocellulose membranes 
(Millipore Ltd.) and diluted accordingly in Type 1 grade water. The nitrogen and phosphorus cellular quotas were estimated as follows:

$$
q_{N}=\frac{N_{o}-N}{X} ; q_{P}=\frac{P_{o}-P}{X},
$$

where $N_{0}\left(\mathrm{gN} \mathrm{L}^{-1}\right)$ and $P_{0}\left(\mathrm{gPO}_{4} \mathrm{~L}^{-1}\right)$ are the initial nitrogen and phosphorus medium concentrations, respectively, and $N, P$, and $X$ are the residual concentrations of nitrogen, phosphorus, and biomass, respectively [52].

\section{Active biomass and carbon equivalent concentration}

The fraction of active biomass (i.e. starch and lipid free biomass) was determined by subtracting starch and lipid concentration from the total biomass (DCW). Acetic acid, starch, lipids, and biomass are reported on a carbon basis by means of conversion factors $\left(\mathrm{gC} \mathrm{g}^{-1}\right): 0.40$ acetate, 0.44 starch, 0.77 lipids, and 0.504 biomass. $C$. reinhardtii cells were assumed to have the elemental composition reported by Eriksen et al. [67].

\section{Estimation of model parameters}

The model presented in this work [Eqs. (16)-(24)] is comprised by 37 kinetic parameters, all appropriately defined in Table 2. The values of 12 kinetic parameters (associated to growth and nitrogen uptake dynamics) were set equivalent to those previously identified by Figueroa-Torres et al. [42]. The remaining kinetic parameters were estimated by minimising the squared relative error between experimental and predicted data:

$$
\min G(P)=\sum_{h=1}^{n h} \sum_{i=1}^{n i} \sum_{k=1}^{n k}\left(\frac{Z_{h, i, k}^{\text {Pred }}(P)-Z_{h, i, k}^{\operatorname{Exp}}}{Z_{h, i, k}^{\operatorname{Exp}}}\right)^{2} .
$$

Here, $G$ is the objective function, $P$ is the parameter set, and $Z$ is the set of predicted or experimental data. Predicted data were generated by solving the model using initial values equivalent to those of nutrient-dependent experiments. $n h, n i$, and $n k$ denote the number of data points in time, number of fitting experimental datasets [3 datasets: (TAP), (Low P), and (High A: Low P)], and number of state variables, respectively. Parameters were restricted by lower $(l b)$ and upper $(u b)$ bounds as per data obtained from literature or experimental analysis. The minimisation problem was solved via a stochastic optimisation routine (simulated annealing) subject to multiple re-starts to approximate the solution around a global minimum. The stochastic solution was then used as initial guess in a deterministic routine (sequential quadratic programming) to generate the final parameter set [68]. Both routines were coded in-house in Matlab R2015a. A sensitivity analysis was carried out for all model parameters and is presented as Additional file 1. As per the sensitivity analysis, 4 parameters were deemed not sensitive $\left(\sigma, k_{S, I}, K_{s, S}\right.$, and $\left.\phi_{L}\right)$ : from which two parameters were set as $\sigma=1$, and $k_{S, I}=1.4$, and the other two were found to have a negligible effect on model predictions when set to 0 , so that $K_{s, S}=0$, and $\phi_{L}=0$.

\section{Supplementary Information}

The online version contains supplementary material available at https://doi. org/10.1186/s13068-021-01912-2.

Additional file 1. Table S1. Initial nutrient concentrations employed during nutrient-dependent cultures. Table S2. p-values obtained by one-way ANOVA (tukey test). Asterisks $\left({ }^{*}\right)$ denote significant differences $\left(p<0.05^{*}, 0.01^{* *}, 0.001^{* * *}\right)$ with respect to (TAP). The analysis was carried out in Origin Pro 2017 (b9.4.1.354). Table S3. Experimental data obtained in C. reinhardtii cultures grown in varying initial acetic acid concentration, with constant $\mathrm{No}=0.382 \mathrm{gN} \mathrm{L}-1$. Table S4. Experimental data obtained in C. reinhardtii cultures grown in varying initial nitrogen concentration, with constant $\mathrm{Po}=0.96 \mathrm{gPO} 4 \mathrm{~L}-1$. Figure S1. Comparison between the modelderived (lines) and experimental (points) data for various C. reinhardtii grown under different initial acetic acid concentrations ( $\mathrm{No}=0.3824 \mathrm{gN}$ $\mathrm{L}-1, \mathrm{Po}=0.096 \mathrm{gPO} 4 \mathrm{~L}-1$ ). Data and simulation corresponds to $\mathrm{t}=192 \mathrm{~h}$. Figure S2. Visual comparison between the effects of the two quotadependent functions on the nutrient uptake rates used in the model. Figure S3. Cultivation dynamics subject to three cultivation conditions, simulated by the a) "saturated" model, and the b) "unsaturated" model. Figure S4. Parity plots comparing predicted and experimental data for both fitting and validating datasets for: a) biomass, b) nitrogen, c) nitrogen quota, d) phosphorus, e) phosphorus quota, f) acetic acid, g) starch, h) lipids, and i) active biomass. Data are the mean of two independent experimental replicates. Figure $\mathbf{S 5}$. Normalised sensitivity of the model state variables with respect to a $1 \%$ increase in , over a $200 \mathrm{~h}$ cultivation period subject to different initial phosphorous concentrations. Parameter colour denotes: green - associated to biomass growth. Figure S6. Normalised sensitivity of the model state variables with respect to a $1 \%$ increase in each model parameter, over a $200 \mathrm{~h}$ cultivation period. Parameter colours denote: green - associated to biomass growth, purple - associated to N uptake, orange - associated to P uptake, and black - associated to starch and lipid formation.

\section{Acknowledgements}

Gonzalo M. Figueroa-Torres kindly acknowledges the Mexican National Council of Science and Technology (CONACyT) for the financial support provided to complete post-graduate studies.

\section{Authors' contributions}

GFT carried out the cultivation experiments and computational work associated to this study, composed and edited the manuscript. JKP supervised the research, discussed the results, commented and edited the manuscript. CT conceived and supervised the research, discussed the results, commented and edited the manuscript. All authors read and approved the final manuscript.

\section{Funding}

Not applicable.

\section{Availability of data and materials}

The main data supporting the findings of this study are available within the article and its additional information. Additional data are available from the corresponding authors on reasonable request.

Ethics approval and consent to participate Not applicable. 


\section{Consent for publication \\ Not applicable.}

\section{Competing interests}

The authors declare that they have no competing interests.

\section{Author details}

${ }^{1}$ Department of Chemical Engineering and Analytical Science, Biochemical and Bioprocess Engineering Group, The University of Manchester, Manchester M13 9PL, UK. ${ }^{2}$ Department of Earth and Environmental Sciences, The University of Manchester, Manchester M13 9PL, UK.

\section{Received: 13 October 2020 Accepted: 21 February 2021}

\section{Published online: 12 March 2021}

\section{References}

1. Gouveia L. Microalgae as a feedstock for biofuels. In: Gouveia L, editor. Berlin: Heidelberg, p. 1-69

2. Köpke M, Dürre P. Biochemical production of biobutanol. In: Handbook biofuels production processes technologies. New York: Elsevier Inc. p. 221-257

3. Scaife MA, Merkx-Jacques A, Woodhall DL, Armenta RE. Algal biofuels in Canada: status and potential. Renew Sustain Energy Rev. 2015;44:620-42.

4. Nigam PS, Singh A. Production of liquid biofuels from renewable resources. Prog Energy Combust Sci. 2011;37:52-68.

5. Suganya T, Varman M, Masjuki HH, Renganathan S. Macroalgae and microalgae as a potential source for commercial applications along with biofuels production: A biorefinery approach. Renew Sustain Energy Rev. 2016:55:909-41.

6. Suparmaniam U, Lam MK, Uemura Y, Lim JW, Lee KT, Shuit SH. Insights into the microalgae cultivation technology and harvesting process for biofuel production: a review. Renew Sustain Energy Rev. 2019:115:109361

7. Choo M-Y, Oi LE, Ling TC, Ng E-P, Lee HV, Juan JC. Conversion of microalgae biomass to biofuels. In: Microalgae cultivation for biofuels production. New York: Academic Press; 2020. p. 149-61.

8. Chen C-Y, Zhao X-Q, Yen H-W, Ho S-H, Cheng C-L, Lee D-J, Bai F-W, Chang J-S. Microalgae-based carbohydrates for biofuel production. Biochem Eng J. 2013;78:1-10

9. Choix FJ, De-Bashan LE, Bashan Y. Enhanced accumulation of starch and total carbohydrates in alginate-immobilized Chlorella spp. induced by Azospirillum brasilense: I Autotrophic conditions. Enzyme Microb Technol. 2012;51:294-9.

10. Enamala MK, Enamala S, Chavali M, Donepudi J, Yadavalli R, Kolapalli B, Aradhyula TV, Velpuri J, Kuppam C. Production of biofuels from microalgae - a review on cultivation, harvesting, lipid extraction, and numerous applications of microalgae. Renew Sustain Energy Rev. 2018;94:49-68.

11. Barsanti L, Gualtieri P. Is exploitation of microalgae economically and energetically sustainable? Algal Res. 2018;31:107-15.

12. Figueroa-Torres GM, Wan Mahmood WMA, Pittman JK, Theodoropoulos C Microalgal biomass as a biorefinery platform for biobutanol and biodiesel production. Biochem Eng J. 2020;153:107396.

13. Zhu L. Biorefinery as a promising approach to promote microalgae industry: an innovative framework. Renew Sustain Energy Rev. 2015:41:1376-84

14. Hariskos I, Posten C. Biorefinery of microalgae-opportunities and constraints for different production scenarios. Biotechnol J. 2014:9:739-52.

15. Trivedi J, Aila M, Bangwal DP, Kaul S, Garg MO. Algae based biorefineryhow to make sense? Renew Sustain Energy Rev. 2015;47:295-307.

16. García Prieto CV, Ramos FD, Estrada V, Villar MA, Diaz MS. Optimization of an integrated algae-based biorefinery for the production of biodiesel, astaxanthin and PHB. Energy. 2017:139:1159-72.

17. Banu JR, Kavitha S, Gunasekaran M, Kumar G. Microalgae based biorefinery promoting circular bioeconomy-techno economic and life-cycle analysis. Bioresour Technol. 2020;302:122822.

18. Harun R, Davidson M, Doyle M, Gopiraj R, Danquah M, Forde G. Technoeconomic analysis of an integrated microalgae photobioreactor, biodiesel and biogas production facility. Biomass Bioenerg. 2011;35:741-7.
19. Pragya N, Pandey KK, Sahoo PK. A review on harvesting, oil extraction and biofuels production technologies from microalgae. Renew Sustain Energy Rev. 2013;24:159-71.

20. RAEng. Sustainability of liquid biofuels. London: Royal Academy of Engineering; 2017.

21. Rashid N, Ur Rehman MS, Sadiq M, Mahmood T, Han J-I. Current status, issues and developments in microalgae derived biodiesel production. Renew Sustain Energy Rev. 2014;40:760-78.

22. Rodolfi L, Chini Zittelli G, Bassi N, Padovani G, Biondi N, Bonini G, Tredici MR. Microalgae for oil: strain selection, induction of lipid synthesis and outdoor mass cultivation in a low-cost photobioreactor. Biotechnol Bioeng. 2009;102:100-12.

23. Shuba ES, Kifle D. Microalgae to biofuels: 'Promising' alternative and renewable energy, review. Renew Sustain Energy Rev. 2018;81:743-55.

24. Markou G, Angelidaki I, Georgakakis D. Microalgal carbohydrates: an overview of the factors influencing carbohydrates production, and of main bioconversion technologies for production of biofuels. Appl Microbiol Biotechnol. 2012:96:631-45.

25. Vitova M, Bisova K, Kawano S, Zachleder V. Accumulation of energy reserves in algae: from cell cycles to biotechnological applications. Biotechnol Adv. 2015;33:1204-18

26. Bajhaiya AK, Dean AP, Driver T, Trivedi DK, Rattray NJW, Allwood JW, Goodacre R, Pittman JK. High-throughput metabolic screening of microalgae genetic variation in response to nutrient limitation. Metabolomics. 2016:12:9.

27. Ball SG, Dirick L, Decq A, Martiat J-C, Matagne R. Physiology of starch storage in the monocellular alga Chlamydomonas reinhardtii. Plant Sci. 1990;66:1-9.

28. Dragone G, Fernandes BD, Abreu AP, Vicente AA, Teixeira JA. Nutrient limitation as a strategy for increasing starch accumulation in microalgae. Appl Energy. 2011:88:3331-5.

29. Yao C-H, Ai J-N, Cao X-P, Xue S. Characterization of cell growth and starch production in the marine green microalga Tetraselmis subcordiformis under extracellular phosphorus-deprived and sequentially phosphorus-replete conditions. Appl Microbiol Biotechnol. 2013:97:6099-110.

30. Concas A, Malavasi V, Costelli C, Fadda P, Pisu M, Cao G. Autotrophic growth and lipid production of Chlorella sorokiniana in lab batch and BIOCOIL photobioreactors: experiments and modeling. Bioresour Technol. 2016:211:327-38.

31. Bekirogullari M, Fragkopoulos IS, Pittman JK, Theodoropoulos C. Production of lipid-based fuels and chemicals from microalgae: an integrated experimental and model-based optimization study. Algal Res. 2017;23:78-87.

32. Chapman SP, Paget CM, Johnson GN, Schwartz J-M. Flux balance analysis reveals acetate metabolism modulates cyclic electron flow and alternative glycolytic pathways in Chlamydomonas reinhardtii. Front Plant Sci. 2015;6:474

33. Johnson X, Alric J. Central carbon metabolism and electron transport in Chlamydomonas reinhardtii: metabolic constraints for carbon partitioning between oil and starch. Eukaryot Cell. 2013;12:776-93.

34. Bekirogullari M, Figueroa-Torres GM, Pittman JK, Theodoropoulos C. Models of microalgal cultivation for added-value products - a review. Biotechnol Adv. 2020;44:107609.

35. Chapter 8-Chlamydomonas in the laboratory. In: Chlamydomonas Sourceb. pp 241-302

36. Fan J, Yan C, Andre C, Shanklin J, Schwender J, Xu C. Oil accumulation is controlled by carbon precursor supply for fatty acid synthesis in Chlamydomonas reinhardtii. Plant Cell Physiol. 2012;53:1380-90.

37. Heldt HW, Chon CJ, Maronde D, Herold A, Stankovic ZS, Walker DA Kraminer A, Kirk MR, Heber U. Role of orthophosphate and other factors in the regulation of starch formation in leaves and isolated chloroplasts. Plant Physiol. 1977;59:1146-55.

38. Gomez-Casati DF, Cortassa S, Aon MA, Iglesias AA. Ultrasensitive behavior in the synthesis of storage polysaccharides in cyanobacteria. Planta. 2003:216:969-75

39. Bekirogullari M, Pittman JK, Theodoropoulos C. Multi-factor kinetic modelling of microalgal biomass cultivation for optimised lipid production. Bioresour Technol. 2018;269:417-25.

40. Goodson C, Roth R, Wang ZT, Goodenough U. Structural correlates of cytoplasmic and chloroplast lipid body synthesis in Chlamydomonas 
reinhardtii and stimulation of lipid body production with acetate boost. Eukaryot Cell. 2011;10:1592-606.

41. Goodenough U, Blaby I, Casero D, et al. The path to triacylglyceride obesity in the sta6 strain of Chlamydomonas reinhardtii. Eukaryot Cell. 2014;13:591-613.

42. Figueroa-Torres GM, Pittman JK, Theodoropoulos C. Kinetic modelling of starch and lipid formation during mixotrophic, nutrient-limited microalgal growth. Bioresour Technol. 2017;241:868-78.

43. Droop MR. Vitamin B12 and marine ecology. IV. The kinetics of uptake, growth and inhibition in Monochrysis Lutheri. J Mar Biol Assoc United Kingdom. 1968;48:689-733.

44. Andrews JF. A mathematical model for the continuous culture of microorganisms utilizing inhibitory substrates. Biotechnol Bioeng. 1968;10:707-23.

45. Laurens LML, Quinn M, Van Wychen S, Templeton DW, Wolfrum EJ. Accurate and reliable quantification of total microalgal fuel potential as fatty acid methyl esters by in situ transesterification. Anal Bioanal Chem. 2012:403:167-78.

46. Lehmuskero A, Skogen Chauton M, Boström T. Light and photosynthetic microalgae: a review of cellular- and molecular-scale optical processes. Prog Oceanogr. 2018;168:43-56.

47. Kwon HK, Oh SJ, Yang H-S. Growth and uptake kinetics of nitrate and phosphate by benthic microalgae for phytoremediation of eutrophic coastal sediments. Bioresour Technol. 2013;129:387-95.

48. Blair MF, Kokabian B, Gude VG. Light and growth medium effect on Chlorella vulgaris biomass production. J Environ Chem Eng. 2014;2:665-74.

49. Mairet F, Bernard O, Lacour T, Sciandra A. Modelling microalgae growth in nitrogen limited photobiorector for estimating biomass, carbohydrate and neutral lipid. In: Prepr. 18th IFAC World Congr. Milano (Italy), p. $10591-10596$

50. Bernard O. Hurdles and challenges for modelling and control of microalgae for $\mathrm{CO} 2$ mitigation and biofuel production. J Process Control. 2011;21:1378-89.

51. Ral J-P, Colleoni C, Wattebled F, et al. Circadian clock regulation of starch metabolism establishes GBSSI as a major contributor to amylopectin synthesis in Chlamydomonas reinhardtii. Plant Physiol. 2006;142:305-17.

52. Bougaran G, Bernard O, Sciandra A. Modeling continuous cultures of microalgae colimited by nitrogen and phosphorus. J Theor Biol. 2010;265:443-54.

53. Mairet F, Bernard O, Masci P, Lacour T, Sciandra A. Modelling neutral lipid production by the microalga Isochrysis aff. galbana under nitrogen limitation. Bioresour Technol. 2011;102:142-9.

54. Droop MR. 25 years of algal growth kinetics a personal view. Bot Mar. 1983;26:99.

55. Levenspiel $\mathrm{O}$. The monod equation: a revisit and a generalization to product inhibition situations. Biotechnol Bioeng. 1980;22:1671-87.
56. Molina-Grima E, García-Camacho F, Sánchez-Pérez JA, Fernández-Sevilla JM, Acién-Fernández FG, Contreras-Gómez A. A mathematical model of microalgal growth in light-limited chemostat culture. J Chem Technol Biotechnol. 1994;61:167-73.

57. Contois DE. Kinetics of bacterial growth: relationship between population density and specific growth rate of continuous cultures. J Gen Microbiol. 1959;21:40-50

58. Cade-Menun BJ, Paytan A. Nutrient temperature and light stress alter phosphorus and carbon forms in culture-grown algae. Mar Chem. 2010;121:27-36.

59. Soru S, Malavasi V, Concas A, Caboni P, Cao G. A novel investigation of the growth and lipid production of the extremophile microalga Coccomyxa melkonianii SCCA 048 under the effect of different cultivation conditions: Experiments and modeling. Chem Eng J. 2019;377:120589.

60. Xin L, Hu H, Ke G, Sun Y. Effects of different nitrogen and phosphorus concentrations on the growth, nutrient uptake, and lipid accumulation of a freshwater microalga Scenedesmus sp. Bioresour Technol. 2010;101:5494-500

61. Philipps G, Happe T, Hemschemeier A. Nitrogen deprivation results in photosynthetic hydrogen production in Chlamydomonas reinhardtii. Planta. 2012;235:729-45.

62. Juneja A, Ceballos R, Murthy G. Effects of environmental factors and nutrient availability on the biochemical composition of algae for biofuels production: a review. Energies. 2013;6:4607-38.

63. Adeniyi OM, Azimov U, Burluka A. Algae biofuel: current status and future applications. Renew Sustain Energy Rev. 2018;90:316-35.

64. Zhan J, Rong J, Wang Q. Mixotrophic cultivation, a preferable microalgae cultivation mode for biomass/bioenergy production, and bioremediation, advances and prospect. Int J Hydrogen Energy. 2017;42:8505-17.

65. Usher PK, Ross AB, Camargo-Valero MA, Tomlin AS, Gale WF. An overview of the potential environmental impacts of large-scale microalgae cultivation. Biofuels. 2014;5:331-49.

66. Hutner SH, Provasoli L, Schatz A, Haskins CP. Some approaches to the study of the role of metals in the metabolism of microorganisms. Proc Am Philos Soc. 1950;94:152-70.

67. Eriksen N, Riisgård F, Gunther W, Lønsmann IJ. On-line estimation of O2 production, $\mathrm{CO} 2$ uptake, and growth kinetics of microalgal cultures in a gas-tight photobioreactor. J Appl Phycol. 2007;19:161-74.

68. Vlysidis A, Binns M, Webb C, Theodoropoulos C. Glycerol utilisation for the production of chemicals: conversion to succinic acid, a combined experimental and computational study. Biochem Eng J. 2011;58-59:1-11.

\section{Publisher's Note}

Springer Nature remains neutral with regard to jurisdictional claims in published maps and institutional affiliations.
Ready to submit your research? Choose BMC and benefit from:

- fast, convenient online submission

- thorough peer review by experienced researchers in your field

- rapid publication on acceptance

- support for research data, including large and complex data types

- gold Open Access which fosters wider collaboration and increased citations

- maximum visibility for your research: over $100 \mathrm{M}$ website views per year

At BMC, research is always in progress.

Learn more biomedcentral.com/submissions 